\title{
Effects of bacterial bio-augmentation on the methane potential from facultative digestion of palm oil mill effluent and empty fruit bunch
}

\begin{abstract}
The methane productivity and biodegradability of facultative single- and co-digestion samples with palm oil mill wastes was evaluated on the effect of bacterial bio-augmentation. The singleand co-digestion substrates were bio-augmented with Bacillus subtillis and a methanogenic mixed culture of anaerobic microorganisms at different loading percentage. The highest methane production was recorded at $0.95 \mathrm{LCH} 4$ from co-digestion sample augmented with $10 \%$ (v/v) B. subtilis while the highest methane yield of $0.7 \mathrm{mLCH} 4 / \mathrm{g}$ volatile solid, attained by single-digestion of palm oil mill effluent with addition of mixed methanogens at $5 \%(\mathrm{v} / \mathrm{v})$. Cumulative methane production for single-digestion increased from $0.17 \mathrm{LCH} 4$ to $0.32 \mathrm{LCH} 4$ in response to the bio-augmentation treatment with 5\% mixed methanogens. Conversely, additional mixed methanogens to co-digestion substrate resulted $75 \%$ reduction in methane production compared to non-augmented co-digestion substrate. Addition of B. subtilis into codigestion was more beneficial than mixed methanogens due to the cellulolytic degradation ability of B. subtilis to digest the lignocellulolytic substances in empty fruit bunch.
\end{abstract}

Keyword: Facultative digestion; EFB; POME; Bio-augmentation; Methane 